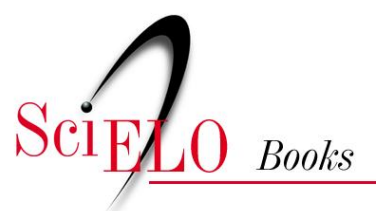

\title{
Primeiros conflitos
}

\author{
Capistrano de Abreu
}

\section{SciELO Books / SciELO Livros / SciELO Libros}

ABREU, C. Primeiros conflitos. In: Capítulos da história colonial [online]. Rio de Janeiro: Centro Edelstein de Pesquisa Social, 2009. pp. 28-31. ISBN: 978-85-7982-071-7.

https://doi.org/10.7476/9788579820717.0004.

\section{() pobumain}

This work is free of known copyright restrictions. http://creativecommons.org/publicdomain/mark/1.0/

Este trabalho está livre de restrições de direito de autor e/ou de direitos conexos conhecidas.

http://creativecommons.org/publicdomain/mark/1.0/

Esta obra está libre de restricciones conocidas de derechos autorales. http://creativecommons.org/publicdomain/mark/1.0/ 


\section{PRIMEIROS CONFLITOS}

Com a chegada dos portugueses coincidiu quase, a dos franceses, que começaram $\operatorname{logo}$ o mesmo comércio de resgate. Na vastidão do litoral podiam ter passado anos sem se encontrar, mas o encontro era fatal, e não havia de ser amigável. Portugal considerava a nova terra propriedade direta e exclusiva da coroa, pelas concessões papais, pelo tratado de limites concluído com a Espanha e pela prioridade do descobrimento. O rei tirava porcentagem dos gêneros levados para além-mar; os armadores queriam auferir lucros de seus esforços e capitais.

A presença dos intrusos prejudicava-os a todos os respeitos: nos mercados europeus, oferecendo os gêneros a preços mais vantajosos, pois não tinham quintos a deduzir, e levando-os diretamente aos mercados consumidores, pois não eram obrigados a parar em Lisboa; nas terras brasílicas, conciliando as simpatias dos naturais, que os agasalhariam com maior carinho, poupar-lhes-iam traições e aleives, dariam preferência nos carregamentos e se habituariam às mercadorias francesas. Ainda por cima havia a questão de princípio: Portugal não admitia que os filhos de outra nação pusessem o pé em terras suas no além-mar.

Desde a Paraíba ao Norte até S. Vicente ao Sul, o litoral estava ocupado por povos falando a mesma língua, procedentes da mesma origem, tendo os mesmos costumes, porém profundamente divididos por ódios inconciliáveis em dois grupos; a si próprio um chamava Tupiniquim, e outro Tupinambá. A migração dos Tupiniquins fora a mais antiga; em diversos pontos os Tupinambás já os tinham repelido para o sertão, como no Rio de Janeiro, na baía de Todos-os-Santos, ao Norte de Pernambuco; em parte de S. Paulo, em Porto Seguro e Ilhéus, nas proximidades de Olinda; na serra de Ibiapaba havia, entretanto, Tupiniquins habitadores do litoral.

Porque os Tupinambás se aliaram constantemente aos franceses e os portugueses tiveram a seu favor os Tupiniquins, não consta da história, mas o fato é incontestável e foi importante; durante anos ficou indeciso se o Brasil ficaria pertencendo aos Peró (portugueses) ou aos Maïr (franceses)

Ainda nos últimos tempos de d. Manuel, começaram os protestos contra a presença dos Maïr; com a acessão de d. João III a situação agravou-se. Reconhecida a inutilidade de embaixadas à corte de França, e de promessas compradas a peso de ouro e jamais cumpridas, o rei de Portugal resolveu desforçar-se. Uma armada de guarda-costa veio em 1527 ao Brasil comandada por Cristóvão Jaques, que já estivera antes na terra e deixara uma feitoria junto a Itamaracá, de volta de uma expedição ao Prata. Desde Pernambuco até a Bahia e talvez Rio de Janeiro, Cristóvão Jaques deu caça aos entrelopos; segundo testemunhos interessados, não conhecia limites sua selvageria, não lhe bastava a morte simples, precisava de torturas e entregava os prisioneiros aos antropófagos para os devorarem. Mesmo assim ainda levou trezentos prisioneiros para o Reino. Devia ter causado um mal enorme aos franceses.

As armadas de guarda-costa eram simples paliativos; só povoando a terra, cortar-se-ia o mal pela raiz. Cristóvão Jaques ofereceu-se a trazer mil povoadores; oferecimento semelhante fez João de Melo da Câmara, irmão do capitão-mor da ilha de S. Miguel. Indignava-se este vendo que até então a gente que vinha ao Brasil limitava-se a comer os alimentos da terra e tomar as índias por mancebas, e propôs trazer numerosas famílias, bois, cavalos, sementes, etc.

Preferiu-se a estas propostas práticas e razoáveis aparelhar nova e mais poderosa armada às ordens de Martim Afonso de Sousa, meio-termo entre armada de guarda-costa e expedição povoadora. Apenas alcançou a costa de Pernambuco, em janeiro de 31, começou a faina de guarda-costa; em poucos dias foram tomadas três naus francesas.

Diogo Leite com duas caravelas foi mandado de Pernambuco para a costa de Este-Oeste, mais desconhecida então que trinta anos antes, quando por elas passara Vicente Yañez Pinzon. Com os outros navios, o capitãomor seguiu para o Sul. Demorou na baía de Todos-os-Santos, na de Guanabara, em Cananeia; continuava para o rio da Prata, e devia entrar em seus planos acompanhar-lhe o curso, pois desde a Europa trazia desarmados bergantins próprios para a exploração, quando a perda da capitânea fê-lo arrepiar caminho para o porto de S. Vicente. Aqui esperou o irmão, Pero Lopes, que em seu lugar mandara às águas platinas.

Desde 1514 chegaram à Europa, levados pela armada de d. Nuno Manuel, os primeiros espécimes de metais preciosos, encontrados nas águas do grande rio. Alguns companheiros de Solis, escapos à sanha dos índios, e 
depois tolerados, confirmaram estes indícios vagos. Na Costa dos Patos alguns deles falavam com entusiasmo em tais riquezas.

Tais notícias nos Patos ou no próprio rio, colheu-as Cristóvão Jaques, cerca de 1522, e levou-as ao Reino. Na feitoria de Itamaracá então fundada, cursavam com tamanha insistência que, em 1526, Sebastião Cabot, ouvindo-as ao aportar em Pernambuco, decidiu logo navegar para Santa Catarina a ir tomar os náufragos de Solis e realizar o descobrimento dos metais anunciados com tanta certeza e insistência. Viera mandado para as Molucas, mas sabia que se triunfasse ninguém lhe lançaria em rosto o desvio, e tanto se capacitou da realidade das minas que não hesitou em transgredir as instruções mais restritas.

Apesar do insucesso final de Cabot, persistiu inabalável a crença nos tesouros platinos; por isso quando, em Cananeia, Francisco de Chaves, grande língua do gentio, pediu gente para fazer uma entrada e prometeu voltar no fim de dez meses com quatrocentos escravos carregados de prata, Martim Afonso não conheceu hesitações. A ideia parecia prática, pois dispensava de acompanhar o litoral até a foz do Prata e subir por este além da fortaleza fundada por Cabot para procurar o Ocidente, onde tais tesouros existiam. O capitão-mor deu quarenta besteiros e quarenta espingardeiros, que sob as ordens de Pero Lobo partiram a 1 de setembro de 1531. Morreram às mãos dos índios, sabe-se vagamente. Pelo mesmo tempo, navegando o oceano Pacífico, Francisco Pizarro alcançou por caminho mais direto as terras dos Incas, procuradas até então pelo lado cisandino.

Depois da perda da capitânea passou Martim Afonso a tratar da segunda parte da sua missão: o povoamento da terra. Em S. Vicente fundou a primeira vila, à beira-mar; algumas léguas para o interior, depois de transposta a serra do Mar, fundou segunda vila, na borda do campo de Piratininga, à margem de um rio cujas águas fluíam para o Ocidente. "Repartiu a gente nestas duas vilas", escreveu Pero Lopes,

e fez nelas oficiais, e pôs tudo em boa obra de justiça, de que a gente toda tomou muita consolação, com verem povoar vilas e ter leis e sacrifícios e celebrar matrimônios e viverem em comunicação das artes, e ser cada um senhor do seu e vestir as injúrias particulares, e ter todos os outros bens da vida segura e conversável.

A situação geográfica destas vilas explica-se pela proximidade das famosas riquezas cobiçadas, pela facilidade de fazer as entradas, dez meses apenas para ir e voltar, garantia Francisco de Chaves. Deslumbrado por tais vantagens, Martim Afonso esqueceu-se dos franceses ou julgou arredados os motivos para temê-los depois da campanha energicamente conduzida por Cristóvão Jaques e por ele continuada com tanto êxito e vigor.

Diogo de Gouveia, português residente em França, seguia desde muito o movimento dos negócios naquele Reino e pensava de modo diverso. Em cartas e el-rei dava-lhe notícias pouco tranquilizadoras, e instava por uma solução real. A solução era não uma vila afastada da zona frequentada, mas diversos povoados na região apetecida do pau-brasil. "Quando lá houver sete ou oito povoações, concluía, estas serão bastantes para defenderem aos da terra que não vendam o brasil a ninguém e não o vendendo as naus não hão de querer lá ir para vir de vazio".

Dir-se-ia que os franceses leram estas palavras previdentes. Até então contentavam-se com o simples resgate, quando muito alguma feitoria. Trataram agora de fundar uma fortaleza, artilhada e com guarnição numerosa. Só assim considerou a corte lusitana "com quanto trabalho se lançaria fora a gente que a povoasse, depois de estar assentado na terra e ter nela feitas algumas forças, como já em Pernambuco começava a fazer". Estes fatos foram conhecidos no Reino graças à nau La Pèlerine, de Marselha, que, procedendo de Pernambuco aonde deixara gente e artilharia, arribou a Málaga. Achava-se no porto uma armada de Portugal, de 10 navios, destinados a Roma; d. Martinho, embaixador, informado da falta de mantimentos que obrigava a arribada, forneceu trinta quintais de biscoutos aos franceses, e convidou-os a navegarem de conserva até Marselha. A cinco milhas de Málaga sobreveio calmaria; a pretexto de concertar a derrota a seguir foram convidados o capitão e o piloto de La Pèlerine para vir a bordo da capitânea portuguesa e, logo, presos, tomado o navio e remetido para Lisboa.

Não foi mais feliz a fortaleza galo-pernambucana. Pero Lopes, terminada a exploração do Prata, e já de viagem para a Europa, bombardeou-a durante dezoito dias, e obrigou-a a render-se. Da guarnição parte foi enforcada; outra, transferida ao Reino, passou longos meses de cativeiro nos calabouços do Algarve. 